\title{
Unidirectional thyristor-based DC-DC converter for HVDC connection of offshore wind farms
}

\author{
Pierre Le Métayer, Piotr Dworakowski, Jose Maneiro \\ SUPERGRID INSTITUTE \\ 23, Rue Cyprian \\ 69100 Villeurbanne, France \\ Tel.: +33763661915 \\ E-Mail: pierre.lemetayer@supergrid-institute.com \\ URL: https://www.supergrid-institute.com
}

\section{Acknowledgements}

This work was supported by a grant overseen by the French National Research Agency (ANR) as part of the "Investissements d'Avenir" Program (ANE-ITE-002-01)

\section{Keywords}

«HVDC», «Converter circuit», « DC collector network», «Wind energy»

\begin{abstract}
This paper introduces a unidirectional MVDC-HVDC converter for 'all DC' connected offshore wind farms. This converter combines the low power losses of thyristor based converters and the control abilities of voltage source converters, together with low power electronics component count. A high step-up ratio is achieved by an input parallel output series configuration. The use of medium frequency is discussed and inductance design conditions are given. A control scheme is proposed and validated by simulations. The converter high efficiency is also observed. The presented analysis shows a potential feasibility and benefits of this novel unidirectional thyristor-based DC-DC converter.
\end{abstract}

\section{Introduction}

In a world where the renewable energy transition becomes more and more urgent, the wind energy is one of the most relied upon source. Indeed the wind energy has become the second most important form of installed generation capacity in 2016 [1]. Moreover, the implementation of wind farms in locations remote from the shore allows steadier and stronger wind compared to onshore installations.

Different methods to bring the produced power back to shore have been investigated. For wind farms located far from shore, HVDC connection is required to keep transmission losses low [2]. An attempt to further reduce these losses is the 'all DC' architecture [3-4], using a MVDC collection grid to bring the power from wind turbines to a central platform where the voltage needs to be stepped up to HVDC. Thus, a high step up ratio MVDC-HVDC DC-DC [5-6] converter that can handle with low losses the power generated by a complete wind farm is a key enabling element that is currently missing in this architecture. This converter volume and weight are important parameters, especially considering offshore platform cost [7]. 

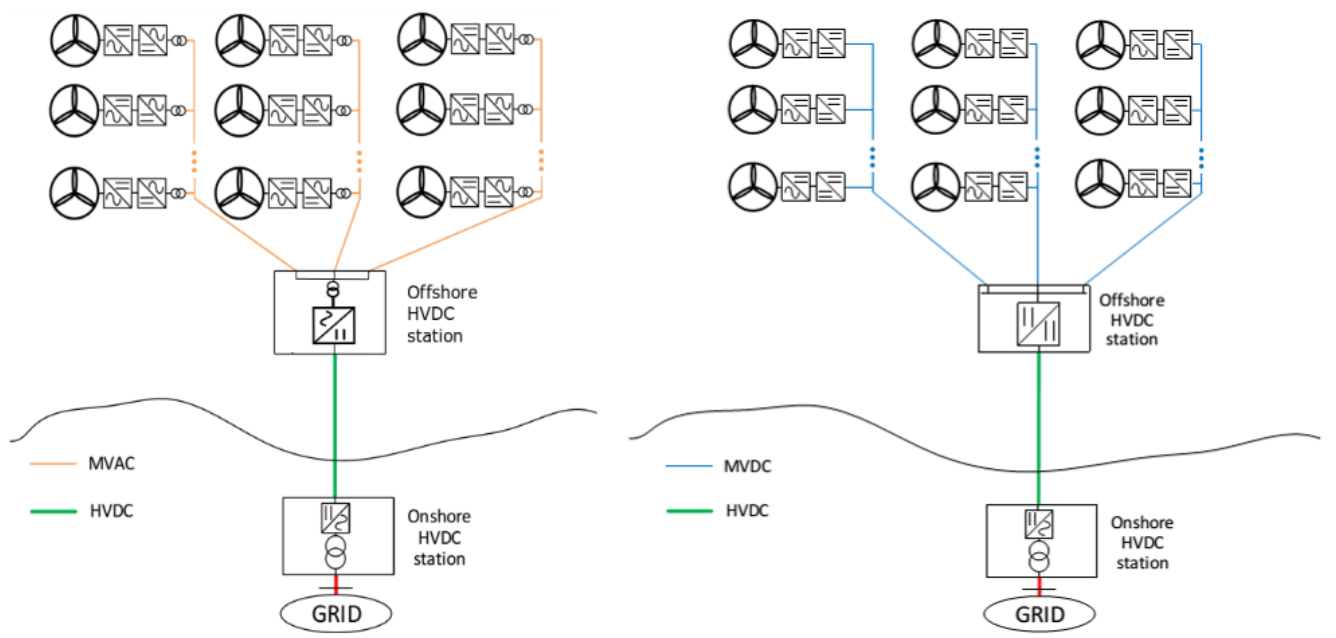

Fig. 1: AC collection offshore wind farm (left), "All DC" offshore wind farm (right)

The power flow of the offshore wind farms being mostly directed towards the shore, the use of unidirectional converters shall be considered offering significant cost reductions. Several step-up DC-DC topologies have been reviewed in [8]. In particular, the unidirectional non-isolated topologies have been considered: chopper-based DC modular converters [9], and the isolated topologies: the phase-shifted full-bridge (PSFB) [10] and the single active bridge (SAB) [11-12]. In order to achieve high voltage stepping ratios [13] while handling important power, converters can be configured in input parallel output series (IPOS) configuration such as presented in [14-16].

The power losses reduction in the transmission systems can be achieved thanks to the use of thyristor valves as in Line Commutated Converter (LCC). A bidirectional thyristor-based converter, the active forced commutated bridge (AFCB), has been proposed in [17-20]. In this topology the thyristor turn-off is forced by a stack of full-bridge chain-link (FB-CL).

One of the main challenges of the "all DC" architecture resides in the use of an isolated DC-DC converter in place of an AC-DC converter and a transformer. The AC solution has one transformation stage less than the isolated DC-DC which makes it difficult for the DC-DC converter to be competitive in terms of costs and power losses. In this article it is proposed to face this challenge by using the AFCB in a SAB configuration, with a diode rectifier on the HVDC port. The AFCB offers low power losses and the SAB configuration offers lower cost compared to a dual active bridge [21]. The proposed topology has only a quarter of the thyristor number compared to its bidirectional counterpart and half the number of FB-CL, foreseeing lower volume, weight and cost. This paper proposes an analysis of the novel topology and controls using the unidirectional AFCB-based step-up DC-DC converter in a 3-cell IPOS configuration for GW range windfarms.
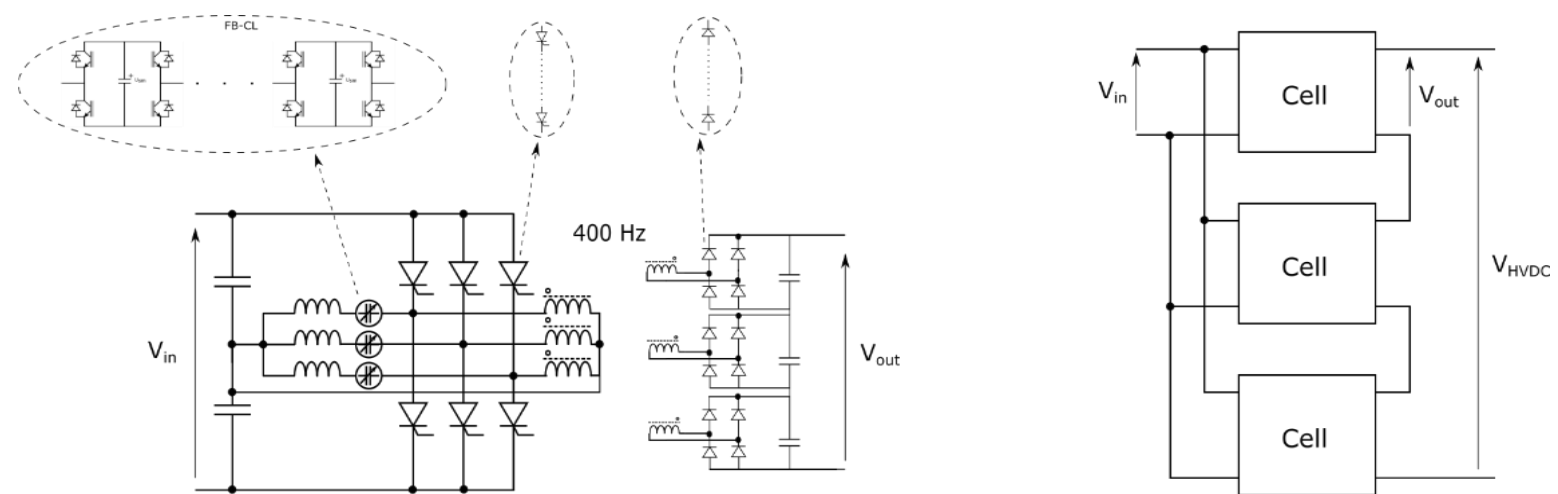

Fig. 2: Proposed DC-DC converter: detailed cell diagram composed of primary bridge, transformer and secondary bridge (left) and 3-cell IPOS configuration (right) 
The principle of operation of the converter is described in the first section, followed by a discussion on its component sizing linked to the use of medium frequency. A control structure is proposed in the third section and it is then validated by simulations. An estimation of losses is also given.

\section{Principle of operation}

As seen in Fig. 2, the cell primary bridge is composed of a thyristor inverter. Using thyristors for the inverter allows low conduction losses, which is of the outmost importance for a converter of such a power rating. On the other hand, compared to an IGBT-based inverter, the possibility of controlling turn-off is lost. In order to solve this problem, the FB-CL are connected between the inverter phase output and the DC bus middle point. The FB-CL arm is composed of an arm inductor and a stack of IGBT based full-bridge cells allowing positive and negative voltage generation.

The FB-CL arm generates the voltage $V_{\text {arm }}$ providing the required negative voltage at thyristor terminals, ultimately forcing its turn-off. As presented in [19] the $V_{\text {arm }}$ is defined by:

$$
-\frac{V_{\text {in }}}{2}-V_{\text {off }} \leq V_{\text {arm }} \leq \frac{V_{\text {in }}}{2}+V_{\text {off }}
$$

where $V_{\text {in }}$ is the input voltage and $V_{\text {off }}$ is the voltage used to force the thyristor valve turn-off. It is defined from the unitary thyristor turn-off voltage $V_{\text {off,th }}$ and the number of thyristors $n_{t h}$ in the valve:

$$
V_{o f f}=n_{t h} \cdot V_{o f f, t h}
$$

The primary and secondary bridge are linked with a 3-phase transformer. The transformer primary winding is Y-connected. At the secondary each transformer winding is connected to a full-bridge diode rectifier. Three cells are connected in IPOS configuration to share the input current and add output voltages, in order to reach the HVDC voltage.

The FB-CL arm and thyristor valve waveforms (for one thyristor leg and FB-CL arm pair) are shown in the Fig. 3.
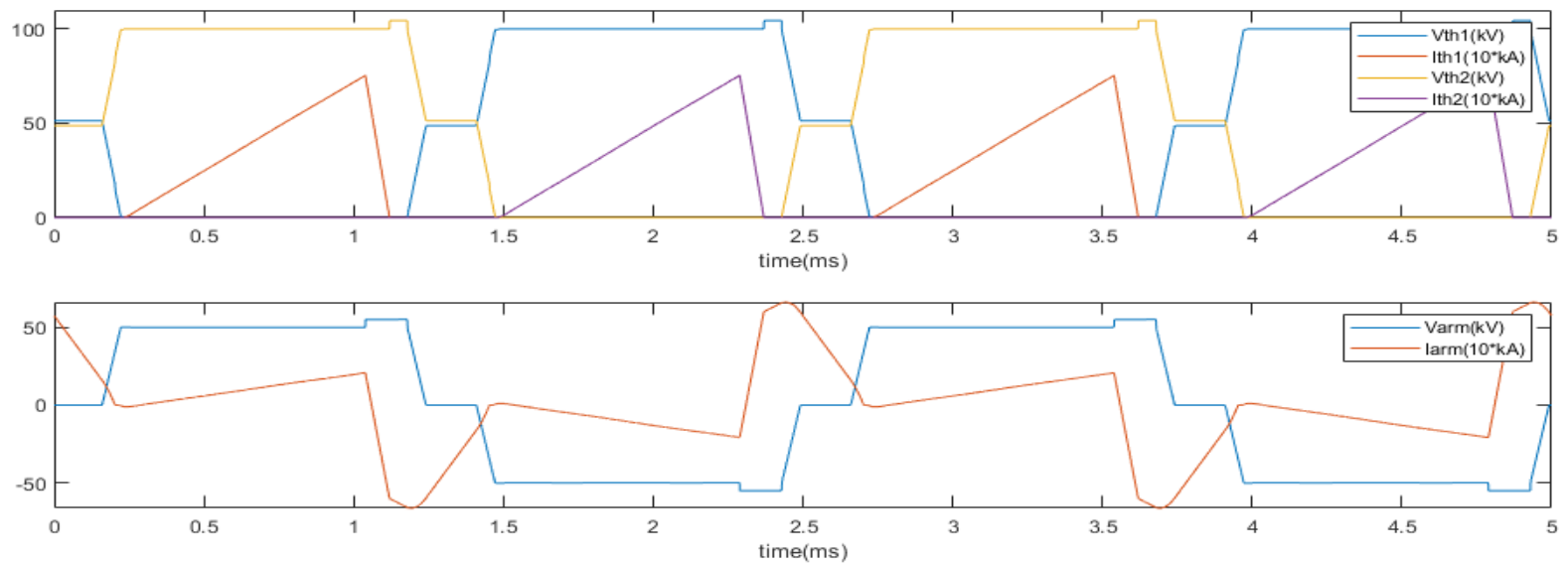

Fig. 3: Thyristor valves waveforms (top), FB-CL arm waveforms (bottom)

It can be seen that when any thyristor in a leg is conducting, it is the FB-CL arm that is conducting the load current. The inverter arms are phase-shifted by $120^{\circ}$. The cells are phase-shifted by $40^{\circ}$, reducing the voltage and current ripples leading to smaller passive components.

\section{Sizing of inductances}

The operation at medium frequency allows the size reduction of the passive elements but also requires the use of fast thyristors. Indeed, throughout the turn-off time $t_{q}$ during which $V_{\text {off }}$ must be applied, it is the FB-CL arm that is conducting the load current, bringing down the converter efficiency. The dynamics of the transition between thyristor valve and FB-CL conduction is dictated by the value of the 
arm inductor $L_{a r m}$, and the shape of the load current by the leakage inductance of the transformer $L_{l k}$. The value of these inductances must then be chosen carefully in order to ensure a long enough application time of $V_{\text {off }}$ on the thyristors.

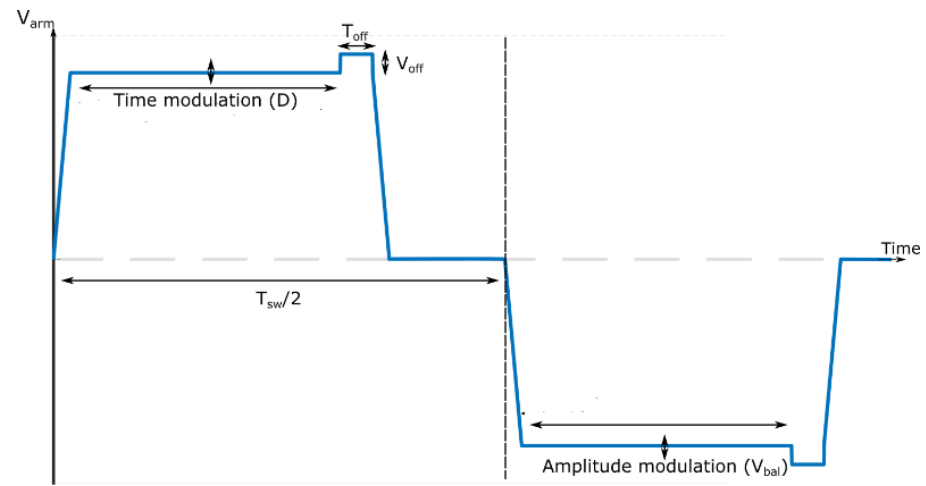

Fig. 4: Definition of quantities on $V_{a r m}$ for arm inductance sizing and control

As shown in Fig. 4 the application time of $V_{\text {off }}$ by the FB-CL arm $t_{\text {off }}$ can be defined as a portion of the half-period $\varepsilon_{o f f}$ :

$$
t_{o f f}=\varepsilon_{o f f} \cdot \frac{1}{2 \cdot f}
$$

where $f$ is the frequency of commutation defined as the inverse of the period $T_{s w}$ presented in Fig. 4 . Because of the presence of the arm inductor, the extra voltage $V_{\text {off }}$ is not applied on the thyristor arm during $t_{\text {off }}$ but during:

$$
t_{q}=t_{o f f}-t_{L a r m}
$$

with $t_{\text {Larm }}$ following the inductance equation:

$$
t_{\text {Larm }}=\frac{L_{a r m} \cdot I_{a c}}{V_{o f f}}
$$

The peak current $I_{a c}$ in the AC link is obtained from the transformer leakage inductance equation:

$$
\begin{aligned}
& I_{a c}=\frac{\left(V_{\text {prim }}-\frac{V_{\text {sec }}}{n}\right) \cdot D}{2 \cdot f \cdot L_{l k}} \\
& t_{\text {Larm }}=\frac{L_{\text {arm }} \cdot\left(V_{\text {prim }}-\frac{V_{\text {sec }}}{n}\right) \cdot D}{L_{l k} \cdot V_{\text {off }} \cdot 2 \cdot f}
\end{aligned}
$$

where $V_{\text {prim }}$ is the primary voltage of a cell transformer and $V_{\text {sec }}$ is the secondary voltage of the transformer. The transformation ratio $n$ is defined as the ratio of the transformer secondary winding turns over the primary wind turns.

One can notice that $t_{\text {Larm }}$ can be reduced by increasing $V_{\text {off }}$. Although it is possible, this would imply an increase in the number of FB-CL and thus an increase of the cost, size and weight of the converter. It is thus recommended to keep $V_{\text {off }}$ as the minimum voltage insuring thyristor valve turn-off.

With $t_{q}$ fixed by the choice of the thyristor $t_{\text {off }}$ must fulfill the relation:

$$
t_{o f f} \geq t_{q}+\frac{L_{a r m} \cdot\left(V_{p r i m}-\frac{V_{s e c}}{n}\right) \cdot D}{L_{l k} \cdot V_{o f f} \cdot 2 \cdot f}
$$




$$
\varepsilon_{o f f} \cdot \frac{1}{2 \cdot f} \geq t_{q}+\frac{L_{a r m} \cdot\left(V_{\text {prim }}-\frac{V_{\text {sec }}}{n}\right) \cdot D}{L_{l k} \cdot V_{o f f} \cdot 2 \cdot f}
$$

As explained in the control principles section, the time modulation index $D$ varies with respect to the transferred power in order to keep $V_{\text {in }}$ to its reference value. Therefore, a condition on the ratio between the FB-CL arm inductance and the transformer leakage inductance can be written for the maximum time modulation index $D_{\max }$ corresponding to the maximum power transfer.

$$
\frac{L_{a r m}}{L_{l k}} \leq \frac{V_{o f f}\left(\varepsilon_{o f f}-2 \cdot f \cdot t_{q}\right)}{\left(V_{\text {prim }}-\frac{V_{s e c}}{n}\right) \cdot D_{\max }}
$$

The value of $\varepsilon_{\text {off }}$ being related to the losses in the FB-CL arms, [17] recommends a value not greater than $10 \%$. Since the ratio of inductances can only be positive, $\varepsilon_{o f f}$ must fulfil:

$$
0.1 \geq \varepsilon_{o f f}>2 \cdot f \cdot t_{q}
$$

The inductance ratio is fixed by (10) in worst case scenario of maximum power transfer. When power transfer is not maximal the time modulation index lowers and $\varepsilon_{\text {off }}$ can thus be reduced as well while still maintaining (10) true, with limitations given by (11).

Equation (11) also gives an idea of the maximum frequency that this converter can operate at for a given thyristor with a turn-off time $t_{q}$.

\section{Control principles}

In the context off an offshore wind farm it is considered that the HVDC voltage is imposed by the onshore converter. Thus, the DC-DC converter must regulate its input MVDC voltage. The presence of capacitor-based FB-CL stacks demands the control of their energies. The proposed control is represented in Fig.5 for one phase of one cell in the IPOS configuration. Thyristor valves control signals $G_{t h 1}$ and $G_{t h 2}$ and FB-CL arm voltage reference signal are phase-shifted by $120^{\circ}$ for following phase of the same cell, and by $40^{\circ}$ for the equivalent cell of following cell.

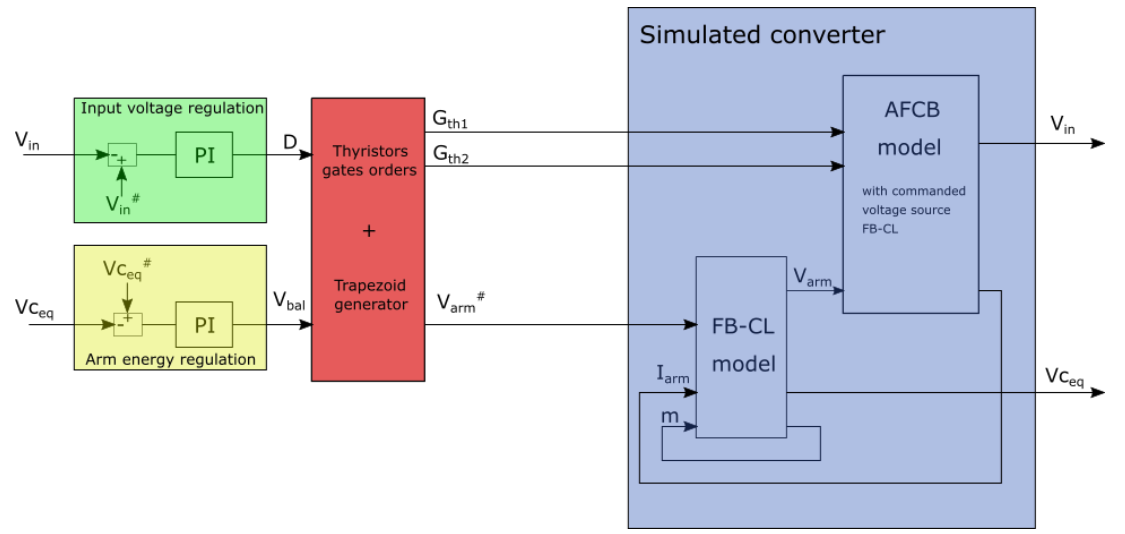

Fig. 5: Proposed control diagram of a cell (only one phase is represented)

The wind turbines connected to the MVDC network are modelled as current sources. These can be considered as an aggregated current source $I_{\text {in }}$ flowing through the input capacitors $C_{1}$ and $C_{2}$ series association $C_{i n}$. In order to control the input voltage, the period of conduction of the thyristors is modulated to charge or discharge the input capacitors.

$$
I_{\text {Cin }}=I_{\text {in }}-I_{\text {conv }}
$$




$$
I_{\text {Cin }}=C_{\text {in }} \frac{d V_{\text {in }}}{d t}
$$

Modulation index $D$ of the thyristor conduction time is considered proportional to the current absorbed by the converter $I_{\text {conv }}$ and is thus calculated by a PI controller from the error between the sum of both input capacitors voltages and the reference $V_{\text {in }}^{\# \text {. }}$.

The FB-CL arm is composed of many capacitors and the arm energy must be regulated at a certain level chosen by the design. Controlling the energy of the stack amounts to control the voltage $V_{c e q}$ of the stack equivalent capacitor $C_{e q}$, series association of submodule capacitors.

$$
E_{a r m}=\frac{1}{2} \cdot C_{e q} \cdot V_{C e q}^{2}
$$

In order to regulate this voltage, the equivalent capacitor is charged or discharged. This is done by modulating $V_{\text {arm }}$ amplitude, a higher value than $V_{i n} / 2$ resulting in a current discharging the equivalent capacitor, and vice versa. The value of the balancing voltage $V_{b a l}$ (amplitude modulation) is calculated by a PI controller from the error between the equivalent capacitor voltage and the stack voltage chosen by design $V_{\text {ceq }}$. The FB-CL arm is modeled by an average model as described in [22]. The equivalent capacitor voltage is calculated from the arm current and the number of currently connected submodules, represented by the utilization index $m$ in figure 5 .

In order to keep a balance between both input capacitors voltages $V_{c 1}$ and $V_{c 2}$, a correction factor dependent on the ratio between these voltages is added. This factor is applied on the arm voltage during the balancing current generation period. Indeed, without this, charging currents could come from only one of the input capacitor and vice versa. This way, one capacitor would charge up to $V_{\text {in }}$ when the other would discharge completely. Thus the arm voltage during the voltage balancing period the positive swings is defined as:

$$
\begin{aligned}
& V_{a r m}=\left(V_{C 1}+V_{b a l}\right) \cdot \frac{V_{C 2}}{V_{C 1}}, \text { if } V_{C 1}>V_{C 2} \\
& V_{a r m}=\left(V_{C 1}+V_{b a l}\right) \cdot \frac{V_{C 1}}{V_{C 2}}, \text { if } V_{C 2}>V_{C 1}
\end{aligned}
$$

And during the negative swings as:

$$
\begin{aligned}
& V_{\text {arm }}=\left(-V_{C 2}-V_{b a l}\right) \cdot \frac{V_{C 2}}{V_{C 1}}, \text { if } V_{C 1}>V_{C 2} \\
& V_{a r m}=\left(-V_{C 1}-V_{b a l}\right) \cdot \frac{V_{C 1}}{V_{C 2}}, \text { if } V_{C 2}>V_{C 1}
\end{aligned}
$$

\section{Simulation Study}

In order to validate the correct operation of the proposed circuit, a simulation model of the converter has been built in Matlab-Simulink. Only one of the three IPOS connected cells has been simulated for computational time sake. The ratings of the simulated system are presented in Table I.

Table I: Ratings of the simulated converter

\begin{tabular}{|l|l|l|}
\hline MVDC voltage & $V_{M V D C}$ & $100 \mathrm{kV}$ \\
\hline HVDC voltage & $V_{H V D C}$ & $\pm 320 \mathrm{kV}$ \\
\hline Farm rated power & $P$ & $1.2 \mathrm{GW}$ \\
\hline
\end{tabular}




\begin{tabular}{|l|l|l|}
\hline Cell input voltage & $V_{\text {in }}$ & $100 \mathrm{kV}$ \\
\hline Cell output voltage & $V_{\text {out }}$ & $213 \mathrm{kV}$ \\
\hline Cell rated power & $P_{u}$ & $400 \mathrm{MW}$ \\
\hline Switching frequency & $f$ & $400 \mathrm{~Hz}$ \\
\hline
\end{tabular}

The frequency of $400 \mathrm{~Hz}$ is chosen in regard of existing fast-thyristor and their turn-off time $t_{q}$. The considered fast-thyristor [23] has a maximum turn-off time of $60 \mu \mathrm{s}$. Following (11), for a chosen $\varepsilon_{o f f}=0.07$, the maximum frequency of the converter is $0.07 /\left(2 * 60^{*} 10^{-6}\right)=583 \mathrm{~Hz}$. From this frequency a safety margin is taken for thyristor valve turn-off might be different from a single thyristor. The use of such medium frequency enables lower size, weight and thus cost of passive components, especially of FB-CL, since the needed capacitance drops with the increase of frequency, and of transformers [24]. Although, the increased operating frequency of such a high power transformer is a challenge. The selected frequency $400 \mathrm{~Hz}$ is relatively high but close to the frequency of $350 \mathrm{~Hz}$ chosen in [25-26].

Control principles are validated by simulating a change in input power and checking the voltage regulation and FB-CL energy balancing.
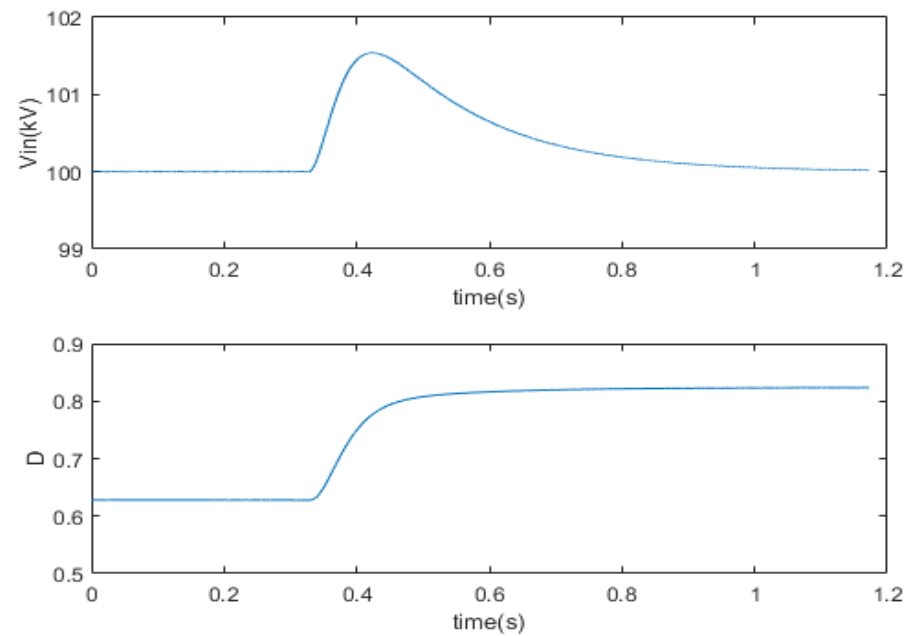

Fig. 7: Input voltage regulation in response to a change from $P_{u} \cdot 2 / 3$ to $P_{u}$
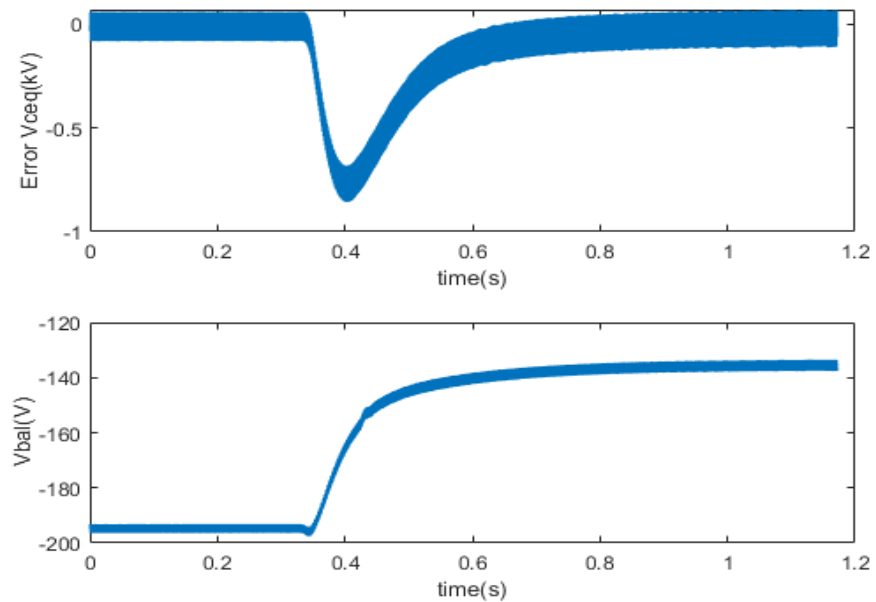

Fig.8: FB-CL arm energy balancing in response to a change from $P_{u} \cdot 2 / 3$ to $P_{u}$

From (10) the inductance ratio is calculated to be 0.023 . The value of the application time of the $V_{\text {off }}$ voltage is checked to be superior to the $t_{q}$ of the thyristor for the worst case, the transfer of the total power $P_{u}$. The value measured in simulation is $63 \mu \mathrm{s}$. 


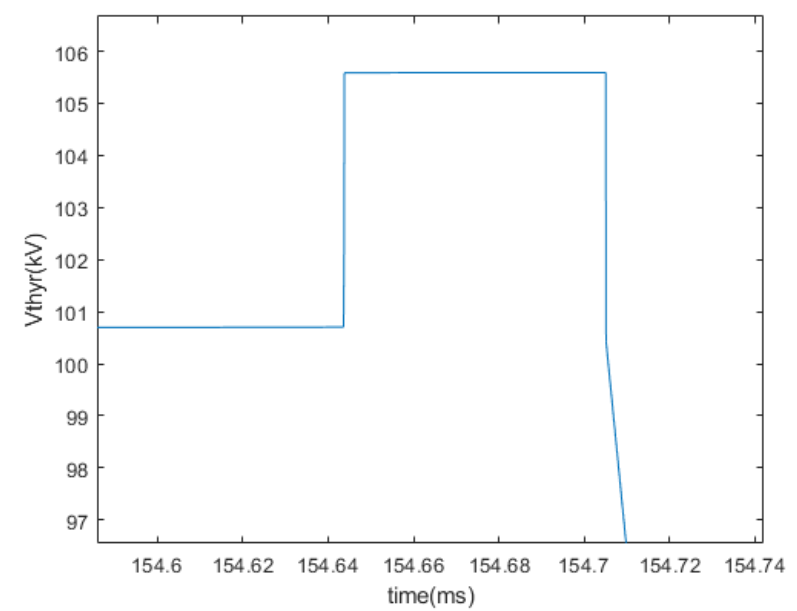

Fig.9: Thyristor valve voltage during $V_{\text {off }}$ application time, for power $P_{u}$

Simulation of the converter currents through its different parts also enabled an efficiency estimation. Power losses in the FB-CL arms are calculated in regard of the methods given in [27]. Transformer losses estimation are based on the work presented in [28]. From these preliminary calculations an efficiency above $98.5 \%$ is expected but a dedicated study is here needed. Such efficiency is higher than those presented in [24] at lower frequency and step-up ratio.

\section{Conclusion}

A unidirectional thyristor-based converter has been proposed for the HVDC connection of "all DC" offshore wind farms. The use of thyristors is believed to achieve lower power losses compared to IGBT DC-DC converters. Medium frequency operation is used to enable a reduction of size weight and thus price of the offshore converter. The consequences of the use of medium frequency on certain design parameters have been discussed. A control method has been proposed to regulate input MVDC voltage and internal energy of the converter. For the case study of a $1.2 \mathrm{GW}$ "all DC" offshore wind farm, a simulation of the converter has been done. The simulations enabled to validate the control strategy and the discussed design recommendations. The potential for high efficiency conversion has also been observed. A cost-performance analysis is now needed to rule on the interest of this converter, and globally of the "all DC" offshore wind farm, compared to other proposed solutions.

\section{References}

[1] Wind Power, "Wind in power: 2016 European statistics," 2017. [Online]. Available: https://windeurope.org/about-wind/statistics/european/wind-in-power-2016.

[2] K. Meah and S. Ula, "Comparative Evaluation of HVDC and HVAC Transmission Systems," in 2007 IEEE Power Engineering Society General Meeting, 2007, pp. 1-5.

[3] M. De Prada Gil, J. L. Domínguez-García, F. Díaz-González, M. Aragüés-Peñalba, and O. Gomis-Bellmunt, "Feasibility analysis of offshore wind power plants with DC collection grid," Renew. Energy, vol. 78, pp. 467-477, Jun. 2015.

[4] R. Ryndzionek and Ł. Sienkiewicz, "Evolution of the HVDC Link Connecting Offshore Wind Farms to Onshore Power Systems," Energies, vol. 13, no. 8, p. 1914, Jan. 2020.

[5] S. Kenzelmann, A. Rufer, D. Dujic, F. Canales, and Y. R. de Novaes, "Isolated DC/DC Structure Based on Modular Multilevel Converter,” IEEE Trans. Power Electron., vol. 30, no. 1, pp. 89-98, Jan. 2015.

[6] S. Cui, J. Hu, M. Stieneker, and R. W. De Doncker, "An Isolated Soft-Switching Hybrid-Source DC-DC Converter for DC Offshore Wind Farms," in 2018 International Power Electronics Conference (IPECNiigata 2018 -ECCE Asia), 2018, pp. 2484-2489.

[7] National Grid, "Electricity ten year statement Appendix E Technology," 2016. [Online]. Available: https://www.nationalgrideso.com/document/47036/download.

[8] J. D. Páez, D. Frey, J. Maneiro, S. Bacha, and P. Dworakowski, “Overview of DC-DC Converters Dedicated to HVdc Grids," IEEE Trans. Power Deliv., vol. 34, no. 1, pp. 119-128, Feb. 2019.

[9] X. Zhang and T. C. Green, "The Modular Multilevel Converter for High Step-Up Ratio DC-DC Conversion," IEEE Trans. Ind. Electron., vol. 62, no. 8, pp. 4925-4936, Aug. 2015. 
[10] N. Hassanzadeh, "Evaluation and comparison of Single-Phase and Three-PhaseFull Bridge topologies for a $50 \mathrm{~kW}$ fast charger Station," Master Thesis, Chalmers University of Technology, Department of Energy and Environment Division of Electric Power Engineering, 2018.

[11] K. Park and Z. Chen, "Analysis and design of a parallel-connected single active bridge DC-DC converter for high-power wind farm applications," in 2013 15th European Conference on Power Electronics and Applications (EPE), 2013, pp. 1-10.

[12] K. Park and Z. Chen, "Control and dynamic analysis of a parallel-connected single active bridge DC-DC converter for DC-grid wind farm application," IET Power Electron., vol. 8, no. 5, pp. 665-671, 2015.

[13] C. D. Barker, C. C. Davidson, D. Trainer, and R. Whitehouse, "Requirements of DC-DC Converters to facilitate large DC Grids," 2012.

[14] J. You, L. Cheng, B. Fu, and M. Deng, "Analysis and Control of Input-Parallel Output-Series Based Combined DC/DC Converter With Modified Connection in Output Filter Circuit," IEEE Access, vol. 7, pp. 58264-58276, 2019.

[15] T. Lagier, P. Ladoux, and P. Dworakowski, "Potential of silicon carbide MOSFETs in the DC/DC converters for future HVDC offshore wind farms," High Volt., vol. 2, no. 4, pp. 233-243, 2017.

[16] P. Wang, L. Zhou, Y. Zhang, J. Li, and M. Sumner, "Input-Parallel Output-Series DC-DC Boost Converter With a Wide Input Voltage Range, For Fuel Cell Vehicles," IEEE Trans. Veh. Technol., vol. 66, no. 9, pp. 7771-7781, Sep. 2017.

[17] P. Li, S. J. Finney, and D. Holliday, "Thyristor based modular multilevel converter with active full-bridge chain-link for forced commutation," in 2016 IEEE 17th Workshop on Control and Modeling for Power Electronics (COMPEL), 2016, pp. 1-6.

[18] P. Li, S. J. Finney, and D. Holliday, “Active-Forced-Commutated Bridge Using Hybrid Devices for High Efficiency Voltage Source Converters,” IEEE Trans. Power Electron., vol. 32, no. 4, pp. 2485-2489, Apr. 2017.

[19] P. Li, G. P. Adam, S. J. Finney, and D. Holliday, "Operation Analysis of Thyristor-Based Front-to-Front Active-Forced-Commutated Bridge DC Transformer in LCC and VSC Hybrid HVDC Networks," IEEE J. Emerg. Sel. Top. Power Electron., vol. 5, no. 4, pp. 1657-1669, Dec. 2017.

[20] P. Li, S. J. Finney, and D. Holliday, "Grid-connection of active-forced-commutated bridge: Power quality and DC fault protection," in IECON 2017 - 43rd Annual Conference of the IEEE Industrial Electronics Society, 2017, pp. 1192-1197.

[21] R. W. De Doncker, D. M. Divan, and M. H. Kheraluwala, "A three-phase soft-switched high power density DC/DC converter for high power applications," in Conference Record of the 1988 IEEE Industry Applications Society Annual Meeting, 1988, pp. 796-805 vol.1.

[22] A. Zama, "Modeling and Control of Modular Multilevel Converters (MMCs) for HVDC applications," Université Grenoble Alpes, 2017.

[23] “Fast Thyristor 5STF 23H2040," ABB, Datasheet, Oct. 2014.

[24] J. D. Páez, J. Maneiro, S. Bacha, D. Frey, and P. Dworakowski, "Influence of the operating frequency on DC-DC converters for HVDC grids," in 2019 21st European Conference on Power Electronics and Applications (EPE' '19 ECCE Europe), 2019, p. P.1-P.10.

[25] D. Jovcic and H. Zhang, "Dual Channel Control With DC Fault Ride Through for MMC-Based, Isolated DC/DC Converter," IEEE Trans. Power Deliv., vol. 32, no. 3, pp. 1574-1582, Jun. 2017.

[26] T. Lüth, M. M. C. Merlin, Tim. C. Green, F. Hassan, and C. D. Barker, "High-Frequency Operation of a DC/AC/DC System for HVDC Applications," IEEE Trans. Power Electron., vol. 29, no. 8, pp. 4107-4115, Aug. 2014.

[27] P. S. Jones and C. C. Davidson, "Calculation of power losses for MMC-based VSC HVDC stations," in 2013 15th European Conference on Power Electronics and Applications (EPE), 2013, pp. 1-10.

[28] A. Fouineau, "Méthodologies de Conception de Transformateurs Moyenne Fréquence pour application aux réseaux haute tension et réseaux ferroviaires," These de doctorat, Lyon, 2019. 